\title{
EXPERT Pathogenesis of arenavirus REVIEWS hemorrhagic fevers
}

Expert Rev. Anti Infect. Ther. 9(1), 49-59 (2011)

\section{Marie-Laurence \\ Moraz ${ }^{1}$ and Stefan Kunz ${ }^{\dagger 1}$}

${ }^{1}$ Institute of Microbiology, University Hospital Center and University of Lausanne, Lausanne, Switzerland ${ }^{+}$Author for correspondence:

Tel.: +41213147743

Fax: +41213144060

stefan.kunz@chuv.ch

Viral hemorrhagic fevers (VHFs) caused by arenaviruses belong to the most devastating emerging human diseases and represent serious public health problems. Arenavirus VHFs in humans are acute diseases characterized by fever and, in severe cases, different degrees of hemorrhages associated with a shock syndrome in the terminal stage. Over the past years, much has been learned about the pathogenesis of arenaviruses at the cellular level, in particular their ability to subvert the host cell's innate antiviral defenses. Clinical studies and novel animal models have provided important new information about the interaction of hemorrhagic arenaviruses with the host's adaptive immune system, in particular virus-induced immunosuppression, and have provided the first hints towards an understanding of the terminal hemorrhagic shock syndrome. The scope of this article is to review our current knowledge on arenavirus VHF pathogenesis with an emphasis on recent developments.

KEYWoRDs: arenavirus $\bullet$ hemorrhagic fever $\bullet$ hemorrhagic shock syndrome $\bullet$ immunosuppression $\bullet$ Junin virus - Lassa virus • vascular endothelium • viral pathogenesis

\section{Arenavirus hemorrhagic fevers are devastating emerging human diseases}

Viral hemorrhagic fevers (VHFs) are severe human diseases that show different clinical courses and are associated with the cardinal symptoms of fever, hemorrhages and shock. A wide variety of viruses that belong to different virus families can cause VHFs, including the filoviruses (Ebola and Marburg hemorrhagic fever $[\mathrm{HF}]$ ), the arenaviruses (Lassa fever, Argentine HF [AHF], Bolivian HF, Venezuelan HF and Brazilian HF), bunyaviruses (Crimean Congo HF and Rift Valley fever) and flaviviruses (Yellow fever and Dengue HF) [1]. The arenaviruses are a large and diverse family of enveloped RNA viruses that include several causative agents of severe VHFs, which belong to the most devastating emerging human diseases and serious public health problems [1,2]. Arenavirus VHFs in humans are acute diseases characterized by fever and, in severe cases, different degrees of hemorrhages associated with a shock syndrome in the terminal stage. The most prevalent pathogen among the arenaviruses is Lassa virus (LASV), the causative agent of Lassa fever that is endemic to West Africa from Senegal to Cameroon and causes several hundred thousand infections per year with thousands of deaths [3]. The mortality of hospitalized Lassa fever patients is $15-30 \%$ and can reach more than $50 \%$ in some outbreaks. There is currently no vaccine available and therapeutic intervention is limited to intensive care and the use of ribavirin, which shows some efficacy when given early in disease. On the South American continent, the arenaviruses Junin virus (JUNV), Machupo virus (MACV), Guanarito virus (GTOV) and Sabia virus (SABV) have emerged as etiological agents of severe VHF in Argentina, Venezuela, Bolivia and Brazil, respectively [2]. The prototypic arenavirus lymphocytic choriomeningitis virus (LCMV), which is distributed worldwide, is also a neglected human pathogen of clinical significance, especially in pediatric medicine $[4,5]$ and represents a threat to immunocompromised individuals [6,7]. Considering the number of people affected and the unaddressed need for better therapeutics, arenaviruses arguably belong to the most neglected tropical pathogens. Apart from the severe humanitarian burden in endemic regions, arenavirus HF cases are regularly imported into metropolitan areas around the globe, placing local populations at risk [8]. This article will briefly cover some general aspects of the classification, epidemiology and basic virology of arenaviruses, and will then provide a more detailed overview of the clinical disease, and in particular the pathogenesis of arenavirus VHFs with an emphasis on recent developments in the field. 


\section{Classification \& epidemiology of arenaviruses}

The Arenaviridae are currently subdivided into two major subgroups, the Old World arenaviruses and the New World arenaviruses $[9,10]$. The Old World lineage contains the prototypic LCMV, the related Dandenong virus and the African viruses LASV, Mopeia, Mobala, Ippy and Morogoro virus. The New World arenaviruses are divided into three Clades, A, B and C. Clade A includes the South American viruses Pichinde virus, Parana virus, Pirital virus, Flexal virus and Allpahuayo virus. A North American Clade A/Rec comprises Whitewater Arroyo, Bear Canyon, and Tamiami, Catarina and Skinner Tank virus. The phylogenetic relationship of these viruses is poorly resolved, but there is evidence that a recombination event between Clade $\mathrm{A}$ and $\mathrm{B}$ viruses may be at the origin of this Clade as reviewed by Emonet et al. [9]. Whitewater Arroyo virus has been associated with three cases of fatal human disease [11,12]. However, a definitive causal relationship has not yet been established. Clade B contains the hemorrhagic viruses JUNV, MACV, GTOV, SABV and the recently emerged Chapare virus, as well as the nonpathogenic viruses Tacaribe (TACV), Amapari and Cupixi. Clade C contains the viruses Oliveros, Latino and Pampa.

In nature, each arenavirus species is carried by one or a limited number of related rodent species, which serve as their natural reservoirs. A possible exception is TACV, which has only been isolated from the fruit-eating bat species Artibeus. The present phylogenetic diversity of arenaviruses is the result of long-term co-evolution between viruses and their corresponding host species, involving vertical and horizontal transfer of viruses within and between populations, respectively, and probably occasional genetic recombination events $[9,10,13]$.

A particular concern is the continued emergence of novel arenaviruses that are associated with fatal human disease. New arenaviruses emerge on average every 3 years [9]. In December 2003, a small cluster of fatal VHF cases was reported in a rural area near the Chapare River in Bolivia, Southern America. Examination of patient samples allowed the isolation and identification of Chapare virus, a novel species of arenavirus phylogenetically closely related to SABV [14]. More recently, in September 2008, a nosocomial outbreak of unexplained VHF occurred in Zambia, Southern Africa. Five patients were involved and four of them died with suspected human-to-human transmission. A high-throughput sequencing approach based on unbiased pyrosequencing revealed the presence of an arenavirus-like genome identified as a new member of the Arenaviridae family called LuJo virus according to its geographic distribution: Lusaka, Zambia and Johannesburg, South Africa [15]. The high mortality of four out of five hospitalized individuals and the strong evidence for human-to-human transmission are of particular concern regarding the epidemiological and disease potential of this new member of the arenavirus family.

Human arenavirus infections occur principally by aerosol or close contact with rodent excreta, contamination of food and drink or via skin abrasions. AHF caused by JUNV has a marked seasonal incidence, coinciding with the maize harvest between April and June when feral rodent populations reach their peak [16]. Agricultural workers and those in rural communities are thus at greatest risk. It is thought that transmission to humans results from the virus being carried on dust particles or by direct ingestion of contaminated foodstuffs.

\section{Molecular \& cell biology of arenaviruses}

The basic virology of arenaviruses has been covered by excellent recent reviews $[2,17]$ and only a short summary will be given here. Arenaviruses are enveloped viruses with a bisegmented negative strand RNA genome and a nonlytic life cycle restricted to the cytoplasm (Figure 1A). Each genomic RNA segment, L (circa $7.3 \mathrm{~kb}$ ) and $\mathrm{S}$ (circa $3.5 \mathrm{~kb}$ ), uses an ambisense coding strategy to direct the synthesis of two polypeptides in opposite orientation, separated by a noncoding intergenic region with a predicted hairpin structure (FIGURe 1B). The S RNA encodes the viral glycoprotein (GP) precursor, which is synthesized as a single polypeptide chain (circa $75 \mathrm{kDa}$ ) and post-translationally cleaved by the cellular proprotein convertase subtilisin kexin isozyme-1/site-1 protease to yield the mature virion GPs GP1 (40-46 kDa) and GP2 (35 kDa) [18-20], and the nucleoprotein (NP; circa $63 \mathrm{kDa}$ ). The L RNA encodes the viral RNA dependent RNA polymerase (RdRp or L polymerase; circa $200 \mathrm{kDa}$ ) and a small RING finger protein Z (circa $11 \mathrm{kDa}$ ).

Attachment to the host cell is mediated by the arenavirus GP1, which is located at the top of the mature GP spike present in the viral envelope. The transmembrane GP2 resembles the fusionactive membrane-proximal parts of other enveloped viruses. The cellular receptor for LASV, most other Old World arenaviruses and Clade C New World arenaviruses is $\alpha$-dystroglycan ( $\alpha-D G$ ), a cell surface receptor for proteins of the extracellular matrix $[21,22]$. The hemorrhagic New World arenaviruses JUNV, MACV, GTOV and SABV can use human transferrin receptor 1 (TfR1) [23]. Upon attachment to the target cell, arenavirus particles are taken up by endocytosis and delivered to acidified endosomes where low $\mathrm{pH}$ induces membrane fusion [24]. New World arenaviruses like JUNV that use human TfR1 enter the cell via clathrin-mediated endocytosis [25]. In contrast, the Old World arenaviruses LASV and LCMV, which depend on $\alpha-D G$, use a distinct and unusual pathway for cell entry that is independent of clathrin, caveolin, dynamin and actin [26-28]. Upon penetration into the cytoplasm, the viral ribonucleoparticles serves as a template for both transcription and replication that is mediated by the arenavirus RdRp L. The L and NP proteins are necessary and sufficient for these initial steps of viral transcription and replication [17]. Formation and release of arenavirus infectious progeny from infected cells occurs by budding during which ribonucleoparticles associate at the cell surface with membranes that are enriched in viral GPs. In arenaviruses, the $\mathrm{Z}$ protein functions as the main driving force for viral budding and resembles the matrix proteins of other enveloped RNA viruses [29,30].

\section{Clinical disease \& pathogenesis of Lassa fever}

LASV was isolated in 1969 after a hospital outbreak in northern Nigeria [31,32], with additional outbreaks in Nigeria, Liberia and Sierra Leone. In 1972, the reservoir of LASV was identified as the rodent Mastomys natalensis [33]. Currently, LASV is 


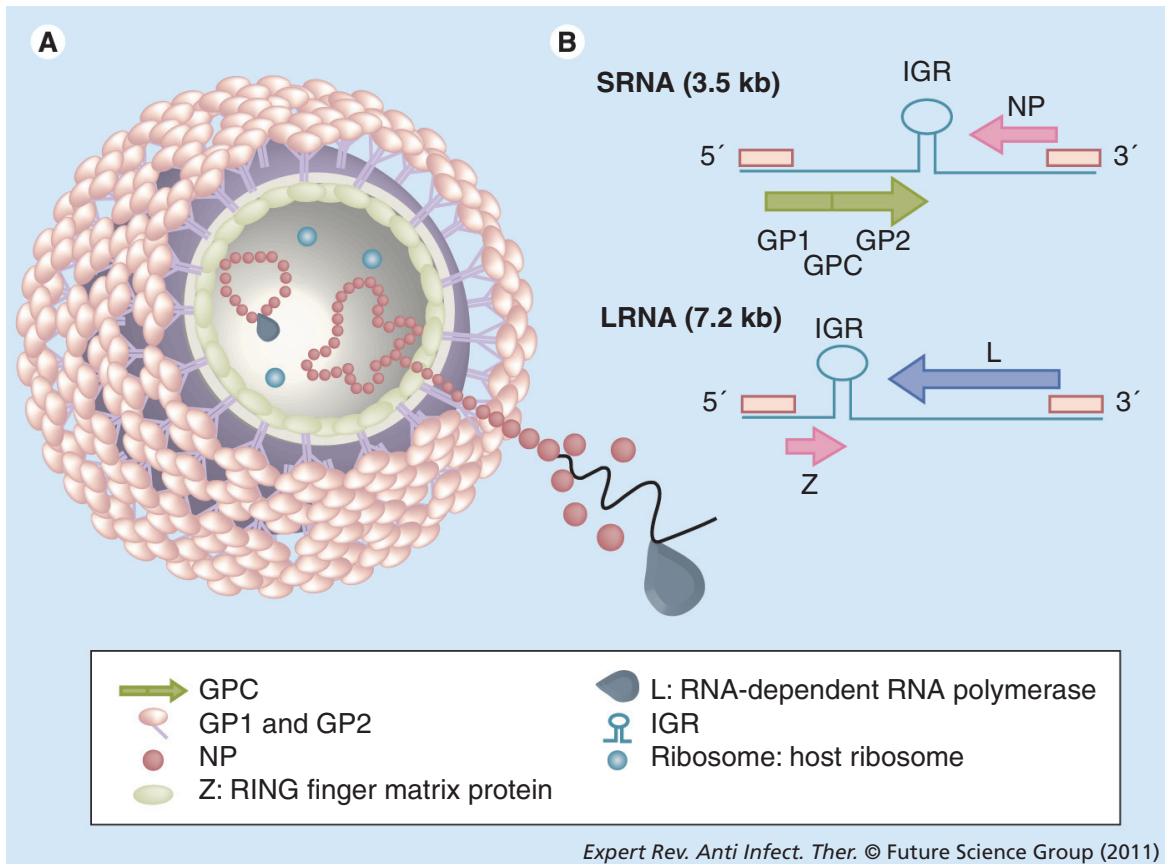

Figure 1. Arenavirus particle and genome organization. (A) Schematic

representation of an arenavirus particle. The viral RNA is packaged into ribonucleoparticles (RNPs) containing the viral NP. The RNA-dependent RNA polymerase $(\mathrm{L})$ is associated with RNP and is required for the initial steps of viral transcription. The matrix protein, Z, associates with the inner leaflet of the viral membrane envelope and interacts with the C-terminal part of the transmembrane GP2 moiety of the mature GP1/GP2 complex decorating the virion surface. The receptor-binding GP1 forms the top part of the GP virion spikes, whereas the transmembrane GP2 part contains the fusion machinery. In their mature form, arenavirus GPs are fully processed and presumably form trimers, similar to other fusion-active viral membrane proteins. (B) The ambisense coding strategy of arenaviruses. Each of the two ssRNA segments, L (circa $7.2 \mathrm{~kb}$ ) and S (3.5 kb), uses an ambisense coding strategy to direct the synthesis of two polypeptides in opposite orientations and is separated by an IGR predicted to have a stable hairpin structure. The 5' ends of the genomic arenavirus RNA cannot serve as a template for translation and viral protein expression requires prior transcription, as in true negative-strand viruses.

GP: Glycoprotein; GPC: Glycoprotein precursor; IGR: Intergenic region; L: RNA-dependent RNA polymerase; NP: Nucleoprotein.

endemic from Senegal to Cameroon [3] with recent emergence in Mali [34]. Reliable epidemiological data are missing from most affected regions, however, available information on seroprevalence for Nigeria, Sierra Leone and Guinea reveal that in some areas, $20-50 \%$ of the adult population have been infected with LASV [35], making LASV a major public health problem. Contact with urine or feces of persistently infected rodents invading human dwellings are the main routes of human transmission, and humanto-human spread can occur by contact with contaminated blood or body fluids [36,37]. The fatality rate of Lassa fever in hospitalized patients is between 15 and $20 \%$ [38], rising to more than $30 \%$ in pregnant women in the third trimester with fetal or neonatal loss of $88 \%$ [39]. The fatality ratio can be as high as $50 \%$ or greater in nosocomial outbreaks [37].

Acute Lassa fever presents with a wide spectrum of clinical manifestations from asymptomatic infection to fatal HF, and diagnosis based on early clinical symptoms is often difficult [38]. After an incubation period of 7-18 days, patients develop fever, weakness and general malaise. A majority of patients develop cough, severe headache and sore throat. Gastrointestinal manifestations such as nausea, diarrhea and vomiting are frequent. Signs of increased vascular permeability such as facial edema and pleural effusions occur in a minority of patients and indicate a poor prognosis. With severe cases leading to death, deterioration is rapid, occurring between the sixth and tenth day of illness with progressive signs and symptoms of pulmonary edema, respiratory distress, shock, signs of encephalopathy accompanied with seizures and coma, and bleeding from mucosal surfaces. Those recovering, generally $2-3$ weeks after disease onset, clear the virus from the blood. A complication late in the course of disease or in early convalescence is sensorineural deafness [40].

A highly predictive factor for the outcome of LASV infection is the extent of viremia. Patients with fatal Lassa fever have higher viral loads at time of hospitalization and are unable to limit viral replication, whereas survivors have lower initial viral load and control the infection [41]. Despite the widespread infection and development of shock in terminal stages of the disease, histological examination of fatal Lassa fever cases showed surprisingly little cellular damage and only a modest infiltration of inflammatory cells [42]. Hepatic lesions in the form of multifocal hepatocellular necrosis were a consistent pathological change $[42,43]$; however, the degree of hepatic tissue damage was insufficient to cause hepatic failure and only minimal recruitment of inflammatory cells was observed. High viral titers were detected in the lung, spleen, kidney, heart and the adrenal gland [42]. Other histological alterations included interstitial pneumonia and acute myocarditis. In the spleen, necrosis occurred predominantly in the marginal zone of the splenic periarteriolar lymphocytic sheath.

A hallmark of fatal LASV infection in humans is the inability of the patient's innate and adaptive immune system to contain the virus, resulting in uncontrolled fatal infection. Instead of being recognized and contained by the host cell's innate defense system, pathogenic arenaviruses are able to subvert the normal mechanisms of innate pathogen recognition. The elucidation of the innate immune defense against arenaviruses and the mechanisms of viral countermeasures have been a particularly active area of arenavirus research in the past 5 years. As is the case for other RNA viruses, the genomic RNA of arenaviruses can be recognized by the cytoplasmic RNA helicases of the retinoic acid-inducible gene I (RIG-I) family, which represent the 
major innate sensors for viral RNA and induce the production of type I interferons (IFNs) $[44,45]$. However, cells infected with arenaviruses are unable to induce a type I IFN response owing to the ability of the viral NP to act as an IFN antagonist [46,47]. Mechanistically, the NPs of arenaviruses block the activation of the transcription factor IFN regulatory factor 3 (IRF3), a major downstream regulator of type I IFN induction via RIG-I helicases [46]. The ability of arenavirus NP to block type I IFN induction is conserved among arenaviruses, with the exception of TACV, whose NP is much less efficient [48]. In contrast to Old World arenaviruses, where the NP appears to be the only IFN antagonist, the matrix protein $\mathrm{Z}$ derived from the New World HF viruses JUNV, MACV, GTOV and SABV is also able to perturb the activation of RIG-I [49]. The Z protein of New World HF viruses directly interacts with RIG-I and blocks the activation of downstream signaling involving IRF3 and NF- $\mathrm{KB}$ via the adaptor mitochondrial antiviral signaling protein. Interestingly, arenaviruses selectively prevent the induction of type I IFNs, but do not perturb signaling induced by the addition of exogenous type I IFNs [46]. The role of the type I IFN response in survivors of LASV infection is not clear. Recent studies in nonhuman primates revealed production of type I IFNs early in LASV infection of animals that survived [50], however, the source of IFN has not been clearly identified and it is at present not clear what role this IFN response plays in protection.

Fatal Lassa fever is characterized by a marked suppression of both branches of the adaptive immune response, cellular and humoral immunity. Surviving Lassa fever patients control the infection primarily by cellular immunity, in particular the antiviral T-cell response [51,52]. By contrast, antibodies play a modest role in acute LASV infection as patients can recover in the absence of a neutralizing antibody response [41]. The marked virus-induced immunosuppression in fatal Lassa fever likely involves infection of antigen-presenting cells (APCs), in particular macrophages and dendritic cells (DCs), crucial populations of professional APCs required to induce the adaptive antiviral immune response (Figure 2) [3]. Infection of human monocyte-derived macrophages and DC with LASV in vitro fails to activate the cells and results in an impairment of their ability to present antigens to $\mathrm{T}$ cells $[53,54]$. LASV infection of macrophages and DCs is not associated with the release of proinflammatory cytokines [53,54] and fatal Lassa fever in humans and nonhuman primates seems not to be associated with massive inflammatory and T-cell-derived cytokine release $[50,55]$.

Another hallmark of LASV infection in humans and nonhuman primates is lymphopenia, which is most pronounced in fatal cases and associated with tissue damage in lymphoid organs [3]. Recent studies in nonhuman primates revealed that both CD4 and CD8 cells, as well as B cells and NK cells, were affected [50]. Since human T and B cells lack a functional LASV receptor [56,57], they are not infected, suggesting an indirect effect that may involve virus-induced immunoregulatory factors. Possible candidates are type I IFNs implicated in lymphopenia observed in experimental infection of the mouse with the related arenavirus LCMV [58].
Although hemorrhages represent a cardinal symptom of arenavirus VHFs, blood loss does normally not account for the fatal outcome of the disease. This is particularly true for Lassa fever, where bleeding is not a salient feature and does not significantly contribute to the shock syndrome [3]. LASV infection in humans is normally associated with only weak thrombocytopenia and mild perturbation of platelet function $[59,60]$. The platelet function defect appears to be mediated by a plasma inhibitor that has not yet been characterized [60]. Only mild vascular lesions were observed in postmortem examination of fatal human Lassa fever cases [42]. In contrast to other VHFs, disseminated intravascular coagulation involving activation of fibrin deposition is virtually absent in arenavirus VHFs (TABLE 1). Virus-induced impairment of vascular function is likely central to fatal Lassa fever (FIgure 2) and perturbation of the function of endothelial cells precedes the onset of shock and death $[59,61]$. The mechanisms by which LASV infection affects endothelial cells are largely unknown and may include direct effects of the virus infection and indirect mechanisms, for example. virusinduced release of soluble factors that impact on endothelial cell function. In other VHFs, in particular Ebola and Marburg HF, alterations of vascular function have been attributed mainly to the virus-induced host responses, in particular excessive production of TNF- $\alpha$, IFN- $\gamma$ and nitric oxide, resembling some aspects of septic shock syndrome $[62,63]$. Initial in vitro studies infecting human monocytes/macrophages and human endothelial cells with LASV provided the first evidence for important differences between the pathogenesis of LASV and filoviruses. LASV infection was highly productive in these cell types without causing an overt cytopathic effect. In the absence of cell damage, LASV infection resulted in reduced levels of proinflammatory cytokines, including TNF- $\alpha$ and IL-8 [64]. Detection of proinflammatory cytokines in the sera of patients with fatal Lassa fever and experimental infection in nonhuman primates have so far revealed little evidence for a 'cytokine storm' as observed in filovirus VHF [50,55]. Although a possible role of host-derived soluble factors in LASV-induced perturbation of endothelial cell function in vivo can at present not be ruled out, it is conceivable that more direct effects of the virus on vascular endothelial cells as a consequence of viral gene expression may underlie at least some of the vascular dysfunction observed in fatal Lassa fever. In summary, the mechanisms underlying the profound shock associated with the terminal stage of fatal Lassa fever in humans are still largely unknown. According to a working model presented in Figure 2, infection of several cell types in different tissues, including the vascular endothelium, the liver and the adrenal cortex, may result in an overall impairment of the regulation of vascular permeability in a direct or indirect way. The terminal shock syndrome may involve an imbalance of fluid distribution between intravascular and interstitial spaces combined with coagulation abnormalities and perhaps dysregulation of blood pressure.

\section{Clinical disease \& pathogenesis of South American hemorrhagic fevers}

Among the South American HF viruses, JUNV, the causative agent of AHF, represents the most important public health problem, whereas MACV, GTOV and SABV cause only sporadic 
outbreaks. JUNV was isolated from fatal VHF cases in the humid Pampas, the major agricultural area of Argentina, in the 1950s $[65,66]$. The rodent Calomys musculinus serves as the main natural reservoir of the virus. The virus is occasionally isolated from other rodents, possibly because of transmission from the natural host population. Former endemic hot spots are currently cooling off, whereas the overall geographic regions affected by the disease increases progressively [67]. AHF is a severe illness with hemorrhagic and/or neurological manifestations and a fatality rate of $15-30 \%$ in untreated cases $[16,67,68]$. JUNV appears to be infectious as aerosols and deposits in the terminal respiratory bronchioles [69]. Upon early replication in the lung, the virus enters into the lymphoid system and spreads systemically. After an incubation period of 1-2 weeks, AHF starts with rather unspecific symptoms: fever, asthenia, muscular pain, dizziness, skin and mucosal rashes, and lymph node swelling. A total of 6-10 days after disease onset, symptoms worsen with cardiovascular, gastrointestinal, renal and neurological involvement, associated with hematologic and hemostatic alterations. Disease manifestations are mainly neurological and/or hemorrhagic. Those who recover from AHF develop an antiviral immune response including antibodies in the second week of disease and clear the virus [70]. In convalescent plasma from AHF survivors, robust titers of neutralizing antiviral antibodies, mainly $\operatorname{IgG}$, can be detected. In fatal cases, viremia is unchecked and patients succumb to a terminal hemorrhagic shock syndrome with a mortality of $15-30 \%$ in the absence of immune plasma therapy $[16,68]$.

Pathological lesions in fatal AHF include generalized vasocongestion with multiple hemorrhages in the gastrointestinal mucosa, different organs, such as the liver, kidney and lungs, as well as subcutaneous tissue. In the kidneys, tubular and papillar necrosis is observed and scattered necrotic hepatocytes are found in the liver. No overt CNS pathology is apparent, despite the frequent manifestation of neurological symptoms. Secondary bacterial infections such as pneumonia are common in AHF. The lesions consistently associated with fatal cases are present

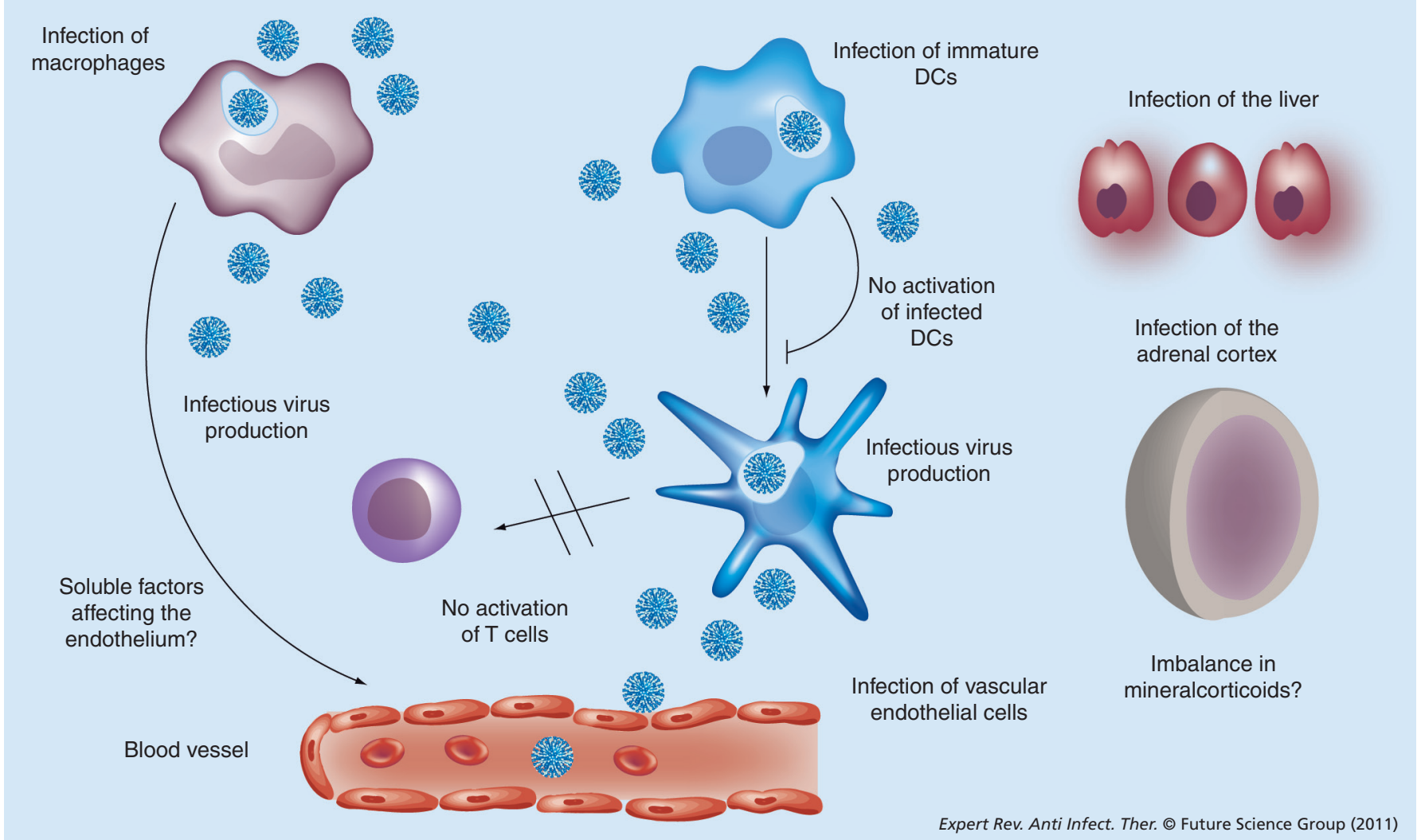

Figure 2. Model for Lassa virus pathogenesis. Macrophages and DCS represent early and preferred targets for Lassa virus (LASV) in human infection. However, instead of being recognized and presented as foreign antigen, LASV establishes productive infection that fails to activate the cells and perturbs their ability to stimulate T cells, contributing to immunosuppression. LASV infection in macrophages and in particular DCs does not result in excessive production of cytokines, but releases significant amounts of infectious virus. Infection of the liver results in enhanced levels of transaminases and hepatocellular necrosis. While the histopathology in the liver is too weak to account for liver failure, infection of hepatocytes may alter the production of serum proteins, possibly affecting hemostasis. Extensive viral replication in the adrenal cortex, where high viral loads are detected, may affect the production of mineralcorticoids leading to fluid imbalance. LASV can productively infect vascular endothelial cells without causing overt cytopathology and vascular lesions are mild in fatal Lassa fever. The mechanisms underlying the alterations in endothelial cell functions that precede shock and death in fatal Lassa fever are largely unknown and may involve direct effect of virus infection as well as effects mediated by as yet undefined soluble factors released by other cells.

DC: Dendritic cell. 


\begin{tabular}{|c|c|c|c|c|}
\hline Parameter & LASV & JUNV & MACV & Ebola \\
\hline Fever & Yes & Yes & Yes & Yes \\
\hline Hypotension & Yes & Yes & Yes & Yes \\
\hline Hemorrhages & Weak $^{+}$ & Occasional & Occasional & Occasional \\
\hline Lymphopenia & Yes & Yes & Yes & Yes \\
\hline Hepatic lesions & Yes & Yes & Yes & Yes \\
\hline Vascular lesions & No & No & No & No \\
\hline Thrombocytopenia & Rare & Yes & Yes & Yes \\
\hline Platelet dysfunction & Mild & Yes & Yes & Yes \\
\hline DIC & $\mathrm{No}^{\ddagger}$ & Rare $^{\S}$ & Rare $^{\S}$ & Yes \\
\hline Infection of MP & Yes & Yes & Yes & Yes \\
\hline Infection of DC & Yes & Yes & Yes & Yes \\
\hline Elevated interferons & No" & Yes & Yes & Yes \\
\hline Elevated cytokines & No" & Yes & Yes & Yes \\
\hline \multicolumn{5}{|c|}{$\begin{array}{l}\text { 'Hemorrhages in LASV are limited to mucosal surfaces and blood loss is mild. } \\
\text { 'Fibrin deposits have been reported in rare cases. } \\
\text { IIn isolated cases, there is biochemical evidence for DIC and detection of fibrin deposits. } \\
\text { "No excessive levels of interferons and cytokines detected in Lassa fever patient sera. } \\
\text { DC: Dendritic cell; DIC: Disseminated intravascular coagulation; JUNV: Junin virus; LASV: Lassa virus; } \\
\text { MACV: Machupo virus; MP: Macrophage. }\end{array}$} \\
\hline
\end{tabular}

von Willebrand factor (vWF) [76]. The latter finding seems to contradict clinical data showing increased $\mathrm{vWF}$ in sera of AHF patients [77] and the reason for this discrepancy is likely another source of vWF in AHF in vivo, such as megakaryocytes/platelets. Of particular interest is the increased production of the vasoactive mediator $\mathrm{NO}$ and prostaglandin $\mathrm{PGI}_{2}$ in endothelial cells infected with a virulent strain of JUNV, but not an avirulent isolate [76], providing a first possible link between viral infection and the increased vascular permeability observed in fatal AHF cases.

A hallmark of fatal AHFs are coagulation abnormalities, including thrombocytopenia and low levels of platelet activity [78]. As in the case of Lassa fever, evidence for an inhibitor of platelet aggregation in plasma of infected patients has been found [60]. However, the exact nature of this inhibitor remains elusive. Recent studies shed light on the mechanism of virus-induced thrombocytopenia employing an in vitro model of human $\mathrm{CD} 43^{+}$cells stimulated with thrombopoietin [79]. JUNV infection

in the lymphatic tissue with widespread necrosis of the splenic white pulp and in the cortical and paracortical areas of the lymph nodes. The bone marrow shows global cell depletion. The highest virus titers are found in the spleen, lymph nodes and lungs, and high levels of viral antigen are found in cells of the monocyte/ macrophage lineage in peripheral blood [71], lymphatic tissue, lung and liver [72]. Patients with AHF have very high levels of IFNs, TNF- $\alpha$, and other inflammatory mediators that correlate with the severity of disease [73-75]. However, at present it is unclear if the enhanced levels of cytokines reflect mainly enhanced levels of viral replication and more widespread infection or if they play a role in immune-mediated pathology similar to fatal filovirus VHFs $[62,63]$.

Virus-induced immunosuppression is also a hallmark of fatal infection with the South American HF viruses. Similar to LASV, JUNV efficiently targets DC early in infection, likely contributing to immunosuppression (Figure 2). In contrast to Lassa fever, AHF manifests with more pronounced hemorrhages, although the extent of vascular damage and blood loss does not account for the fatal outcome [16]. The hemorrhagic syndrome in AHF is attributed to coagulation alterations and marked thrombocytopenia, possibly in combination with virus and cytokine-induced vascular damage and does, in contrast to other VHF, generally not involve disseminated intravascular coagulation (TABLE $\mathbf{1}$ ).

Several lines of evidence implicate infection of vascular endothelial cells in AHF pathogenesis. Infection of cultured endothelial cells with JUNV did not cause overt cytopathic effects but altered expression of cell adhesion molecules ICAM-1 and VCAM-1 and reduced secretion of coagulation factors, such as the prothrombic of $\mathrm{CD}_{4} 3^{+}$precursor cells did not affect proliferation and cell viability but markedly perturbed the differentiation of megakaryocytes resulting in reduced thrombopoiesis at the levels of proplatelet formation and platelet release. Interestingly, perturbation of thrombopoiesis was not dependent on direct infection of cells, but seems to be, at least in part, mediated by a bystander effect that involves type I IFNs. A remarkable aspect of AHF is the fact that some patients die in absence of hemorrhagic disease and manifest mainly with neurological symptoms [16]. The pathophysiological basis for the neurological syndrome that is present to a variable degree in AHF patients is currently largely unknown.

$\mathrm{MACV}$ is also a rodent-borne pathogen that caused serious outbreaks of HF in Bolivia in the 1960s [80], but the number of cases has declined since. Human-to-human transmission has been reported [81]. GTOV emerged as the cause of Venezuelan HF in the 1990s [82,83]. Based on their close phylogenetic relationship to JUNV, infections with MACV $[84,85]$ and GTOV $[82,83,86]$ resemble AHF in their pathology, clinical manifestations and mortality.

While no specific treatments or vaccines have been established for MACV and GTOV, a live-attenuated JUNV has been developed and is used in high-risk groups in endemic areas [87]. Current therapy of AHF infection involves the administration of immune plasma from convalescent patients [88], which is effective when started during the first week of disease and critically depends on the titers of neutralizing antibodies. Immune plasma therapy reduces mortality from $15-30 \%$ to less than $1 \%$. Circa $10 \%$ of patients develop a self-limiting late neurological syndrome, whose pathophysiology is unknown. 


\section{Insights into the pathogenesis of arenavirus hemorrhagic fevers from new animal models}

The investigation of arenavirus pathogenesis critically depends on suitable animal models. Nonhuman primates are still considered the major relevant model for Lassa fever, in particular rhesus and cynomolgus monkeys (Macaca mulatta and Macaca fascicularis, respectively). Experimental studies in these nonhuman primates largely reproduce the pathology of human Lassa fever at the systemic and histological level, including hepatocellular necrosis, interstitial pneumonia, increased blood transaminase levels, and hemorrhagic signs and symptoms [50,51,89-94]. As in the human disease, the terminal shock syndrome includes hypovolemia, hypotension and acute respiratory distress. A recent study comparing antiviral immune responses between fatal and nonfatal LASV infection in cynomolgus monkeys revealed that fatal infection was associated with only weak activation of antiviral $\mathrm{T}$ cells and monocytes, a delayed and weak antibody response resulting in unchecked viremia, shock and death. Nonfatal infection was characterized by a vigorous antiviral T-cell response, activation of monocytes and effective control of viral replication [50]. The similarities with clinical findings in human Lassa fever underline the potential of this model for future studies. Marmosets have recently been described as an alternative nonhuman primate model for LASV infection [95]. Another powerful model for LASV infection in nonhuman primates uses the closely related LCMV, which is a BSL2/3 pathogen $[96,97]$. This model has recently been used for comprehensive transcriptome analysis in the blood and liver of rhesus monkeys infected with a lethal dose of LCMV that has provided an invaluable source for the search for candidate genes involved in arenavirus VHF pathogenesis and biomarkers for diagnostic purposes [98,99].

A major challenge in LASV research has been the lack of a mouse model for LASV that allows the application of useful mouse genetics for studies on LASV pathogenesis in vivo, mainly owing to the fact that normal laboratory mouse strains are resistant to LASV infection. A recent study found that mice expressing humanized MHC class I failed to control LASV infection and developed fatal VHF [100]. Interestingly, in this model, depletion of $\mathrm{T}$ cells prevented disease, irrespective of viremia, indicating a role for T cells in VHF pathogenesis. It will be of great interest to compare the observations from this novel small animal model with established nonhuman primate models and human infection. Another important lesson learned from this novel model is to consider the possibility of T-cell-mediated pathology in the development of novel Lassa fever vaccine strategies.

Other important BSL2/3 models for arenavirus VHF are the infection of Pichinde virus in guinea pigs (reviewed in [101]) and the infection of Syrian golden hamsters with Pirital virus [102,103]. Several experimental animal models exist for JUNV pathogenesis, including mice [104-107], guinea pigs [108-110] and rats [111], as well as New and Old World primates [112-116]. A particularly interesting small animal model for JUNV infection has recently been established using the JUNV Romero strain in guinea pigs and largely recapitulates the pathological findings in human AHF [117], holding great potential for basic research on JUNV pathogenesis and evaluation of novel drugs and vaccine candidates.

\section{Expert commentary \& five-year view}

The past years have seen an impressive progress in our understanding of the basic molecular and cellular biology of arenaviruses. In particular, the advent of a powerful reverse genetic system for arenaviruses [118-120] paves the way for sophisticated structure-function studies and the molecular dissection of the mechanisms of virus-host interaction in vitro and also in vivo. Over the years, much has been learned about the pathogenesis of arenaviruses at the cellular level, in particular their ability to subvert the host cell's innate antiviral defenses [45-49]. Key IFN antagonists of arenaviruses have been discovered and the mechanisms by which the viruses block innate antiviral signaling elucidated. Other in vitro studies have shed light on the impact of arenavirus infection on the differentiation and function of cells targeted by hemorrhagic arenaviruses in vivo, including APCs such as macrophages and DCs [53,54], endothelial cells [76], and megakaryocytes [79] involved in platelet formation. At the same time, novel animal models provided important new information about the interaction of hemorrhagic arenaviruses with the host's adaptive immune system, in particular virus-induced immunosuppression, and provided the first hints towards an understanding of the terminal hemorrhagic shock syndrome [50,98-100,117]. However, many questions remain unanswered. In particular, the pathogenesis of Lassa fever appears to be rather atypical with little evidence for immunopathological mechanisms and largely unknown mechanisms underlying the vascular dysfunction involved in the terminal shock syndrome. As more subtle, direct effects of virus replication and gene expression may be responsible for the perturbation of endothelial cell function, future research involving suitable cell culture models for human endothelium, which allow detailed analysis of virus-induced cell biological and biochemical alterations, will be of great importance. Advances in endothelial cell culture, combined with high resolution confocal microscopy and the ability to measure endothelial cell functions such as transendothelial electrical resistance and hydraulic conductivity in live cells will allow monitoring of subtle, virus-induced functional changes as a consequence of arenavirus infection. The availability of a powerful reverse genetic system for arenaviruses [118-120] combined with suitable well-controlled in vitro experimental systems may allow the identification of viral proteins and their cellular targets implicated in virus-induced changes in the major cell types targeted by LASV in vivo, including APCs such as DCs and vascular endothelial cells. The identification of cellular proteins and signaling pathways affected by virus infection and the characterization of the molecular interactions involved over the next 5 years will open new avenues for the development of drugs that could prevent arenavirus-induced endothelial cell dysfunction associated with fatal arenavirus VHFs. In addition, recently developed novel diagnostic tools, including more sensitive molecular probes for viral nucleic acids and new antibodies against LASV proteins, will allow a better assessment of the extent of viral infection of the endothelium and consequent functional alterations in vivo. The recent development of novel and promising small animal models for human Lassa fever and AHF, as well as refinements 
of established nonhuman primate models for LASV will greatly facilitate the validation of mechanistic findings obtained in vitro in the systemic context and allow evaluation of novel therapeutic strategies in preclinical studies.

\section{Acknowledgements}

The authors thank Amalio Telenti (University of Lausanne) and Michael BA Oldstone (Scripps Research Institute, La Jolla) for their generous support.

\section{Financial \& competing interests disclosure}

This work was supported by the Swiss National Science Foundation grant No. 3100A0-120250/1 (Stefan Kunz), the Prix Leenaards 2009 pour la promotion de la recherche scientifique (Stefan Kunz) and a research grant of the Foundation Vontobel (Marie-Laurence Moraz and Stefan Kunz). The authors have no other relevant affiliations or financial involvement with any organization or entity with a financial interest in or financial conflict with the subject matter or materials discussed in the manuscript apart from those disclosed.

No writing assistance was utilized in the production of this manuscript.

\section{Key issues}

- Viral hemorrhagic fevers (VHFs) caused by arenaviruses are among the most devastating emerging human diseases and represent serious public health problems. There is no licensed vaccine against these pathogens and therapeutic options are limited.

- A particular concern with arenaviruses is the continued emergence of new viruses that are associated with severe VHFs, as illustrated by the emergence of Chapare virus in 2003 and Lujo virus in 2008.

- Arenavirus VHFs in humans are acute diseases characterized by fever and, in severe cases, different degrees of hemorrhages associated with a shock syndrome in the terminal stage. Blood loss in arenavirus VHF does not account for the fatal outcome, and the pathophysiology underlying the terminal shock syndrome is not yet fully understood.

- Based on its clinical and pathological features, Lassa fever presents as a rather atypical VHF. Postmortem examination of fatal Lassa fever cases show surprisingly little tissue damage and only modest inflammation with absence of disseminated intravascular coagulation in the terminal stage.

- Fatal arenavirus VHFs are characterized by marked immunosuppression of the host, resulting in uncontrolled viral spread and replication associated with hemorrhagic shock. The immunosuppression associated with fatal disease is likely related to the fact that hemorrhagic arenaviruses efficiently target antigen-presenting cells such as macrophages and, in particular, dendritic cells, and perturb their function in antigen presentation.

- Arenaviruses can efficiently block the host cell's antiviral interferon response with the viral nucleoprotein and, in some species, also the $Z$ protein, acting as interferon antagonists. Efficient blocking of the host innate antiviral defense by arenaviruses may contribute to the inability of the host to contain virus infection in fatal arenavirus VHF.

- A number of novel animal models for VHFs have been developed in past years and hold much promise for future studies on arenavirus pathology in vivo.

\section{References}

Papers of special note have been highlighted as:

- of interest

-• of considerable interest

$\downarrow_{1}$ Geisbert TW, Jahrling PB. Exotic emerging viral diseases: progress and challenges. Nat. Med. 10 (12 Suppl.), S110-S121 (2004).

2 Buchmeier MJ, de la Torre JC, Peters CJ. Arenaviridae: the viruses and their replication. In: Fields Virology. Knipe DL, Howley PM (Eds.) Lippincott-Raven, Philadelphia, PA, USA, 1791-1828 (2007).

- 3 McCormick JB, Fisher-Hoch SP. Lassa fever. Curr. Top. Microbiol. Immunol. 262, 75-109 (2002).

- 4 Barton LL, Mets MB, Beauchamp CL. Lymphocytic choriomeningitis virus: emerging fetal teratogen. Am. J. Obstet. Gynecol. 187(6), 1715-1716 (2002).

\5 Jamieson DJ, Kourtis AP, Bell M, Rasmussen SA. Lymphocytic choriomeningitis virus: an emerging obstetric pathogen? Am. J. Obstet. Gynecol. 194(6), 1532-1536 (2006).
-6 Fischer SA, Graham MB, Kuehnert MJ et al. Transmission of lymphocytic choriomeningitis virus by organ transplantation. $N$. Engl. J. Med. 354(21), 2235-2249 (2006).

-7 Palacios G, Druce J, Du L et al. A new arenavirus in a cluster of fatal transplantassociated diseases. N. Engl. J. Med. 358(10), 991-998 (2008).

- Describes the discovery of a new arenavirus associated with fatal cases of infection in transplantation patients and is of particular interest regarding the technologies used for pathogen discovery.

-8 Borio L, Inglesby T, Peters CJ et al. Hemorrhagic fever viruses as biological weapons: medical and public health management. JAMA 287(18), 2391-2405 (2002).

- Emonet SF, de la Torre JC, Domingo E, Sevilla N. Arenavirus genetic diversity and its biological implications. Infect. Genet. Evol. 9(4), 417-429 (2009).

- 10 Charrel RN, de Lamballerie X, Emonet S. Phylogeny of the genus Arenavirus. Curr. Opin. Microbiol. 11(4), 362-368 (2008).
(CDC) CfDCaP. Fatal illnesses associated with a new world arenavirus - California, 1999-2000. MMWR Morb. Mortal. Wkly Rep. 49(31), 709-711 (2000).

$\checkmark 12$ Enserink M. Emerging diseases. New arenavirus blamed for recent deaths in California. Science 289(5481), 842-843 (2000).

13 Charrel RN, Lemasson JJ, Garbutt M et al. New insights into the evolutionary relationships between arenaviruses provided by comparative analysis of small and large segment sequences. Virology 317(2), 191-196 (2003).

- 14 Delgado S, Erickson BR, Agudo R et al. Chapare virus, a newly discovered arenavirus isolated from a fatal hemorrhagic fever case in Bolivia. PLoS Pathog. 4(4), e1000047 (2008).

- Reports the discovery of Chapare virus, a new arenavirus associated with fatal viral hemorrhagic fevers (VHFs) in Bolivia.

Briese T, Paweska JT, McMullan LK et al. Genetic detection and characterization of Lujo virus, a new hemorrhagic fever- 
associated arenavirus from southern Africa. PLoS Pathog. 5(5), e1000455 (2009).

- Describes the identification of a new arenavirus in South Africa that has been associated with fatal VHF and suspected human-to-human transmission.

- 16 Weissenbacher MC, Laguens RP, Coto CE. Argentine hemorrhagic fever. Curr. Top. Microbiol. Immunol. 134, 79-116 (1987).

17 de la Torre JC. Molecular and cell biology of the prototypic arenavirus LCMV: implications for understanding and combating hemorrhagic fever arenaviruses. Ann. $N Y$ Acad. Sci. 1171(Suppl. 1), E57-E64 (2009).

$\checkmark 18$ Lenz O, ter Meulen J, Klenk HD, Seidah NG, Garten W. The Lassa virus glycoprotein precursor GP-C is proteolytically processed by subtilase SKI-1/S1P. Proc. Natl Acad. Sci. USA 98(22), 12701-12705 (2001).

-19 Beyer WR, Popplau D, Garten W, von Laer $\mathrm{D}$, Lenz O. Endoproteolytic processing of the lymphocytic choriomeningitis virus glycoprotein by the subtilase SKI-1/S1P. J. Virol. 77(5), 2866-2872 (2003).

20 Rojek JM, Lee AM, Nguyen N, Spiropoulou $\mathrm{CF}, \mathrm{Kunz}$ S. Site 1 protease is required for proteolytic processing of the glycoproteins of the South American hemorrhagic fever viruses Junin, Machupo, and Guanarito. J. Virol. 82(12), 6045-6051 (2008).

-21 Cao W, Henry MD, Borrow P et al. Identification of $\alpha$-dystroglycan as a receptor for lymphocytic choriomeningitis virus and Lassa fever virus [see comments]. Science 282(5396), 2079-2081 (1998).

-22 Kunz S. Receptor binding and cell entry of Old World arenaviruses reveal novel aspects of virus-host interaction. Virology 387(2), 245-249 (2009).

23 Radoshitzky SR, Abraham J, Spiropoulou CF et al. Transferrin receptor 1 is a cellular receptor for New World haemorrhagic fever arenaviruses. Nature 446(7131), 92-96 (2007).

-. Describes the discovery of human TfR1 as the receptor for the South American hemorrhagic fever arenaviruses. The discovery of the cellular receptor of these viruses is of great importance considering their pathogenesis.

24 Borrow P, Oldstone MB. Mechanism of lymphocytic choriomeningitis virus entry into cells. Virology 198(1), 1-9 (1994).

25 Martinez MG, Cordo SM, Candurra NA. Characterization of Junin arenavirus cell entry. J. Gen. Virol. 88(Pt 6), 1776-1784 (2007).
26 Quirin K, Eschli B, Scheu I, Poort L Kartenbeck J, Helenius A. Lymphocytic choriomeningitis virus uses a novel endocytic pathway for infectious entry via late endosomes. Virology 378(1), 21-33 (2008).

27 Rojek JM, Perez M, Kunz S. Cellular entry 40 of lymphocytic choriomeningitis virus. J. Virol. 82(3), 1505-1517 (2008).

28 Rojek JM, Sanchez AB, Nguyen NT, de la Torre JC, Kunz S. Different mechanisms of cell entry by human-pathogenic Old World and New World arenaviruses. J. Virol. 82(15), 7677-7687 (2008).

29 Perez M, Craven RC, de la Torre JC. The small RING finger protein $\mathrm{Z}$ drives arenavirus budding: implications for antiviral strategies. Proc. Natl Acad. Sci. USA 100(22), 12978-12983 (2003).

- 30 Strecker T, Eichler R, Meulen J et al. Lassa virus $\mathrm{Z}$ protein is a matrix protein and sufficient for the release of virus-like particles [corrected]. J. Virol. 77(19), 10700-10705 (2003).

- 31 Frame JD, Baldwin JM Jr, Gocke DJ, Troup JM. Lassa fever, a new virus disease of man from West Africa. I. Clinical description and pathological findings. Am. J. Trop. Med. Hyg. 19(4), 670-676 (1970).

- 32 Buckley SM, Casals J. Lassa fever, a new virus disease of man from West Africa. 3. Isolation and characterization of the virus. Am. J. Trop. Med. Hyg. 19(4), 680-691 (1970).

-33 Monath TP, Newhouse VF, Kemp GE, Setzer HW, Cacciapuoti A. Lassa virus isolation from Mastomys natalensis rodents during an epidemic in Sierra Leone. Science 185(147), 263-265 (1974).

4 Safronetz D, Lopez JE, Sogoba N et al. Detection of Lassa virus, Mali. Emerg. Infect. Dis. 16(7), 1123-1126 (2010).

- 35 Richmond JK, Baglole DJ. Lassa fever: epidemiology, clinical features, and social consequences. Br. Med. J. 327(7426), 1271-1275 (2003).

36 McCormick JB, Webb PA, Krebs JW, Johnson KM, Smith ES. A prospective study of the epidemiology and ecology of Lassa fever. J. Infect. Dis. 155(3), 437-444 (1987).

Fisher-Hoch SP, Tomori O, Nasidi A et al. Review of cases of nosocomial Lassa fever in Nigeria: the high price of poor medical practice. Br. Med. J. 311(7009), 857-859 (1995).

38 McCormick JB, King IJ, Webb PA et al. A case-control study of the clinical diagnosis and course of Lassa fever. J. Infect. Dis. 155(3), 445-455 (1987).
39 Price ME, Fisher-Hoch SP, Craven RB, McCormick JB. A prospective study of maternal and fetal outcome in acute Lassa fever infection during pregnancy. Br. Med. J. 297(6648), 584-587 (1988).

40 Cummins D, McCormick JB, Bennett D et al. Acute sensorineural deafness in Lassa fever. JAMA 264(16), 2093-2096 (1990).

41 Johnson KM, McCormick JB, Webb PA, Smith ES, Elliott LH, King IJ. Clinical virology of Lassa fever in hospitalized patients. J. Infect. Dis. 155(3), 456-464 (1987).

\42 Walker DH, McCormick JB, Johnson KM et al. Pathologic and virologic study of fata Lassa fever in man. Am. J. Pathol. 107(3), 349-356 (1982).

43 McCormick JB, Walker DH, King IJ et al. Lassa virus hepatitis: a study of fatal Lassa fever in humans. Am. J. Trop. Med. Hyg. 35(2), 401-407 (1986).

44 Habjan M, Andersson I, Klingstrom J et al. Processing of genome 5' termini as a strategy of negative-strand RNA viruses to avoid RIG-I-dependent interferon induction. PLoS One 3(4), e2032 (2008).

45 Zhou S, Cerny AM, Zacharia A, Fitzgerald KA, Kurt-Jones EA, Finberg RW. Induction and inhibition of the type I interferon responses by distinct components of lymphocytic choriomeningitis virus. J. Virol. 84(18), 9452-9462 (2010).

46 Martinez-Sobrido L, Zuniga EI, Rosario D, Garcia-Sastre A, de la Torre JC. Inhibition of the type I interferon response by the nucleoprotein of the prototypic arenavirus lymphocytic choriomeningitis virus. J. Virol. 80(18), 9192-9199 (2006).

-. Identified the nucleoprotein of arenaviruses as a potent antagonist of the cellular type I interferon response. This was the first report demonstrating the existence of an interferon antagonist in arenaviruses.

47 Martinez-Sobrido L, Emonet S, Giannakas P, Cubitt B, Garcia-Sastre A, de la Torre JC. Identification of amino acid residues critical for the anti-interferon activity of the nucleoprotein of the prototypic arenavirus lymphocytic choriomeningitis virus. J. Virol. 83(21), 11330-11340 (2009).

Martinez-Sobrido L, Giannakas P, Cubitt B, Garcia-Sastre A, de la Torre JC. Differential inhibition of type I interferon induction by arenavirus nucleoproteins. J. Virol. 81(22), 12696-12703 (2007).

Fan L, Briese T, Lipkin WI. Z proteins of New World arenaviruses bind RIG-I and interfere with type I interferon induction. J. Virol. 84(4), 1785-1791 (2010). 
50 Baize S, Marianneau P, Loth P et al. Early and strong immune responses are associated with control of viral replication and recovery in lassa virus-infected cynomolgus monkeys. J. Virol. 83(11), 5890-5903 (2009).

-51 Fisher-Hoch SP, Hutwagner L, Brown B, McCormick JB. Effective vaccine for lassa fever. J. Virol. 74(15), 6777-6783 (2000).

- 52 ter Meulen J, Badusche M, Kuhnt K et al. Characterization of human CD4(+) T-cell clones recognizing conserved and variable epitopes of the Lassa virus nucleoprotein. J. Virol. 74(5), 2186-2192 (2000).

53 Baize S, Kaplon J, Faure C, Pannetier D, Georges-Courbot MC, Deubel V. Lassa virus infection of human dendritic cells and macrophages is productive but fails to activate cells. J. Immunol. 172(5), 2861-2869 (2004).

-54 Mahanty S, Hutchinson K, Agarwal S, McRae M, Rollin PE, Pulendran B. Cutting edge: impairment of dendritic cells and adaptive immunity by Ebola and Lassa viruses. J. Immunol. 170(6), 2797-2801 (2003).

- Described the perturbation of antigen presentation to $T$ cells by dendritic cells upon Lassa virus (LASV) infection.

55 Mahanty S, Bausch DG, Thomas RL et al. Low levels of interleukin-8 and interferoninducible protein-10 in serum are associated with fatal infections in acute Lassa fever. $J$. Infect. Dis. 183(12), 1713-1721 (2001).

-56 Reignier T, Oldenburg J, Noble B et al. Receptor use by pathogenic arenaviruses. Virology 353(1), 111-120 (2006).

-57 Rojek JM, Spiropoulou CF, Campbell KP, Kunz S. Old World and Clade C New World arenaviruses mimic the molecular mechanism of receptor recognition used by $\alpha$-dystroglycan's host-derived ligands. J. Virol. 81(11), 5685-5695 (2007).

-58 McNally JM, Zarozinski CC, Lin MY, Brehm MA, Chen HD, Welsh RM. Attrition of bystander CD8 T cells during virusinduced T-cell and interferon responses. J. Virol. 75(13), 5965-5976 (2001).

- 59 Fisher-Hoch S, McCormick JB, Sasso D, Craven RB. Hematologic dysfunction in Lassa fever. J. Med. Virol. 26(2), 127-135 (1988).

60 Cummins D, Fisher-Hoch SP, Walshe KJ et al. A plasma inhibitor of platelet aggregation in patients with Lassa fever. Br. J. Haematol. 72(4), 543-548 (1989).

-61 Fisher-Hoch SP, Mitchell SW, Sasso DR, Lange JV, Ramsey R, McCormick JB. Physiological and immunologic disturbances associated with shock in a primate model of Lassa fever. J. Infect. Dis. 155(3), 465-474 (1987).

-62 Aleksandrowicz P, Wolf K, Falzarano D, Feldmann H, Seebach J, Schnittler H. Viral haemorrhagic fever and vascular alterations. Hamostaseologie 28(1-2), 77-84 (2008).

63 Schnittler HJ, Feldmann H. Viral hemorrhagic fever - a vascular disease? Thromb. Haemost. 89(6), 967-972 (2003).

64 Lukashevich IS, Maryankova R, Vladyko AS et al. Lassa and Mopeia virus replication in human monocytes/macrophages and in endothelial cells: different effects on IL-8 and TNF- $\alpha$ gene expression. J. Med. Virol. 59(4), 552-560 (1999).

65 Arribalzaga RA. New epidemic disease due to unidentified germ: nephrotoxic, leukopenic and enanthematous hyperthermia. Dia. Med. 27(40), 1204-1210 (1955).

-66 Parodi AS, Greenway DJ, Rugiero HR et al. Concerning the epidemic outbreak in Junin. Dia. Med. 30(62), 2300-2301 (1958).

67 Peters CJ. Human infection with arenaviruses in the Americas. Curr. Top. Microbiol. Immunol. 262, 65-74 (2002).

68 Harrison LH, Halsey NA, McKee KT Jr et al. Clinical case definitions for argentine hemorrhagic fever. Clin. Infect. Dis. 28(5), 1091-1094 (1999).

-69 Kenyon RH, McKee KT Jr, Zack PM et al. Aerosol infection of rhesus macaques with Junin virus. Intervirology 33(1), 23-31 (1992).

70 de Bracco MM, Rimoldi MT, Cossio PM et al. Argentine hemorrhagic fever. Alterations of the complement system and anti-Junin-virus humoral response. $N$. Engl. J. Med. 299(5), 216-221 (1978).

-71 Ambrosio AM, Enria DA, Maiztegui JI. Junin virus isolation from lymphomononuclear cells of patients with Argentine hemorrhagic fever. Intervirology 25(2), 97-102 (1986).

72 Gonzalez PH, Cossio PM, Arana R, Maiztegui JI, Laguens RP. Lymphatic tissue in Argentine hemorrhagic fever. Pathologic features. Arch. Pathol. Lab. Med. 104(5), 250-254 (1980).

73 Levis SC, Saavedra MC, Ceccoli C et al. Correlation between endogenous interferon and the clinical evolution of patients with Argentine hemorrhagic fever. J. Interferon Res. 5(3), 383-389 (1985).

74 Heller MV, Saavedra MC, Falcoff R, Maiztegui JI, Molinas FC. Increased tumor necrosis factor- $\alpha$ levels in Argentine hemorrhagic fever. J. Infect. Dis. 166(5), 1203-1204 (1992).
Marta RF, Montero VS, Hack CE, Sturk A, Maiztegui JI, Molinas FC. Proinflammatory cytokines and elastase- $\alpha$-1-antitrypsin in Argentine hemorrhagic fever. Am. J. Trop. Med. Hyg. 60 (1), 85-89 (1999).

Gomez RM, Pozner RG, Lazzari MA et al. Endothelial cell function alteration after Junin virus infection. Thromb. Haemost. 90(2), 326-333 (2003).

Molinas FC, de Bracco MM, Maiztegui JI. Hemostasis and the complement system in Argentine hemorrhagic fever. Rev. Infect. Dis. 11(Suppl. 4), S762-S770 (1989).

Heller MV, Marta RF, Sturk A et al. Early markers of blood coagulation and fibrinolysis activation in Argentine hemorrhagic fever. Thromb. Haemost. 73(3), 368-373 (1995).

Pozner RG, Ure AE, Jaquenod de Giusti C et al. Junin virus infection of human hematopoietic progenitors impairs in vitro proplatelet formation and platelet release via a bystander effect involving type I IFN signaling. PLoS Pathog. 6(4), e1000847 (2010).

- Interesting paper describing a possible mechanism by which Junin virus infection perturbs platelet formation.

-80 Johnson KM, Kuns ML, Mackenzie RB, Webb PA, Yunker CE. Isolation of Machupo virus from wild rodent Calomys callosus. Am. J. Trop. Med. Hyg. 15(1), 103-106 (1966).

- 81 Kilgore PE, Peters CJ, Mills JN et al. Prospects for the control of Bolivian hemorrhagic fever. Emerg. Infect. Dis. 1(3), 97-100 (1995).

-82 Salas R, de Manzione N, Tesh RB et al. Venezuelan haemorrhagic fever. Lancet 338(8774), 1033-1036 (1991).

83 Tesh RB, Jahrling PB, Salas R, Shope RE. Description of Guanarito virus (Arenaviridae: Arenavirus), the etiologic agent of Venezuelan hemorrhagic fever. Am. J. Trop. Med. Hyg. 50 (4), 452-459 (1994).

84 Stinebaugh BJ, Schloeder FX, Johnson KM, Mackenzie RB, Entwisle G, De Alba E. Bolivian hemorrhagic fever. A report of four cases. Am. J. Med. 40 (2), 217-230 (1966).

Johnson KM, Halstead SB, Cohen SN. Hemorrhagic fevers of Southeast Asia and South America: a comparative appraisal. Prog. Med. Virol. 9, 105-158 (1967).

86 de Manzione N, Salas RA, Paredes H et al. Venezuelan hemorrhagic fever: clinical and epidemiological studies of 165 cases. Clin. Infect. Dis. 26(2), 308-313 (1998). 
-87 Enria DA, Barrera Oro JG. Junin virus vaccines. Curr. Top. Microbiol. Immunol. 263, 239-261 (2002).

-88 Enria DA, Briggiler AM, Sanchez Z. Treatment of Argentine hemorrhagic fever. Antiviral Res. 78(1), 132-139 (2008).

-89 Callis RT, Jahrling PB, DePaoli A. Pathology of Lassa virus infection in the rhesus monkey. Am. J. Trop. Med. Hyg. 31(5), 1038-1045 (1982).

90 Geisbert TW, Jones S, Fritz EA et al. Development of a new vaccine for the prevention of Lassa fever. PLoS Med. 2(6), e183 (2005).

-91 Jahrling PB, Hesse RA, Eddy GA, Johnson KM, Callis RT, Stephen EL. Lassa virus infection of rhesus monkeys: pathogenesis and treatment with ribavirin. J. Infect. Dis. 141(5), 580-589 (1980).

-92 Jahrling PB, Peters CJ. Passive antibody therapy of Lassa fever in cynomolgus monkeys: importance of neutralizing antibody and Lassa virus strain. Infect. Immun. 44(2), 528-533 (1984).

\33 Jahrling PB, Peters CJ, Stephen EL. Enhanced treatment of Lassa fever by immune plasma combined with ribavirin in cynomolgus monkeys. J. Infect. Dis. 149(3), 420-427 (1984).

94 Walker DH, Johnson KM, Lange JV, Gardner JJ, Kiley MP, McCormick JB. Experimental infection of rhesus monkeys with Lassa virus and a closely related arenavirus, Mozambique virus. J. Infect. Dis. 146(3), 360-368 (1982).

-95 Carrion R Jr, Brasky K, Mansfield K et al. Lassa virus infection in experimentally infected marmosets: liver pathology and immunophenotypic alterations in target tissues. J. Virol. 81(12), 6482-6490 (2007).

96 Lukashevich IS, Djavani M, Rodas JD et al. Hemorrhagic fever occurs after intravenous, but not after intragastric, inoculation of rhesus macaques with lymphocytic choriomeningitis virus. J. Med. Virol. 67(2), 171-186 (2002).

97 Lukashevich IS, Tikhonov I, Rodas JD et al. Arenavirus-mediated liver pathology: acute lymphocytic choriomeningitis virus infection of rhesus macaques is characterized by high-level interleukin- 6 expression and hepatocyte proliferation. J. Virol. 77(3), 1727-1737 (2003).

-98 Djavani MM, Crasta OR, Zapata JC et al. Early blood profiles of virus infection in a monkey model for Lassa fever. J. Virol. 81(15), 7960-7973 (2007).
- Interesting paper characterizing the protective immune response against LASV in a relevant human primate model.

-99 Djavani M, Crasta OR, Zhang Y et al. Gene expression in primate liver during viral hemorrhagic fever. Virol. J. 6, 20 (2009).

- 100 Flatz L, Rieger T, Merkler D et al. T cell-dependence of Lassa fever pathogenesis. PLoS Pathog. 6(3), e1000836 (2010).

- Describes a new small animal model for LASV infection using mice transgenic for human MHC.

101 Liang Y, Lan S, Ly H. Molecular determinants of Pichinde virus infection of guinea pigs - a small animal model system for arenaviral hemorrhagic fevers. Ann. NY Acad. Sci. 1171(Suppl. 1), E65-E74 (2009).

- 102 Xiao SY, Zhang H, Yang Y, Tesh RB. Pirital virus (Arenaviridae) infection in the syrian golden hamster, Mesocricetus auratus: a new animal model for arenaviral hemorrhagic fever. Am. J. Trop. Med. Hyg. 64(3-4), 111-118 (2001).

103 Sbrana E, Mateo RI, Xiao SY, Popov VL, Newman PC, Tesh RB. Clinical laboratory, virologic, and pathologic changes in hamsters experimentally infected with Pirital virus (Arenaviridae): a rodent model of Lassa fever. Am. J. Trop. Med. Hyg. 74(6), 1096-1102 (2006).

104 Weissenbacher MC, de Guerrero LB, Boxaca MC. Experimental biology and pathogenesis of Junin virus infection in animals and man. Bull. World Health Organ. 52(4-6), 507-515 (1975).

105 Barrios HA, Rondinone SN, Blejer JL, Giovanniello OA, Nota NR. Development of specific immune response in mice infected with Junin virus. Acta. Virol. 26(3), 156-164 (1982).

- 106 Weissenbacher MC, Calello MA, Quintans CJ, Panisse H, Woyskowsky NM, Zannoli $\mathrm{VH}$. Junin virus infection in genetically athymic mice. Intervirology 19(1), 1-5 (1983).

- 107 Campetella OE, Galassi NV, Sanjuan N, Barrios HA. Susceptible adult murine model for Junin virus. J. Med. Virol. 26(4), 443-451 (1988).

108 Scolaro LA, Mersich SE, Damonte EB. Experimental infection of suckling mice with a host range mutant of Junin virus. J. Med. Virol. 34(4), 237-240 (1991).

109 Kenyon RH, Green DE, Maiztegui JI, Peters CJ. Viral strain dependent differences in experimental Argentine hemorrhagic fever (Junin virus) infection of guinea pigs. Intervirology 29(3), 133-143 (1988).
110 Kenyon RH, Green DE, Eddy GA, Peters CJ. Treatment of junin virus-infected guinea pigs with immune serum: development of late neurological disease. $J$. Med. Virol. 20(3), 207-218 (1986).

111 Remesar MC, Blejer JL, Lerman GD, Dejean C, Nejamkis MR. Protection against encephalitis in rats caused by a pathogenic strain of the Junin virus, using peripheral inoculation of an attenuated strain. Rev. Argent. Microbiol. 21(3-4), 120-126 (1989).

- 112 Weissenbacher MC, Calello MA, Colillas OJ, Rondinone SN, Frigerio MJ. Argentine hemorrhagic fever: a primate model. Intervirology 11(6), 363-365 (1979).

113 McKee KT Jr, Mahlandt BG, Maiztegui JI, Eddy GA, Peters CJ. Experimental Argentine hemorrhagic fever in rhesus macaques: viral strain-dependent clinical response. J. Infect. Dis. 152(1), 218-221 (1985).

114 McKee KT Jr, Green DE, Mahlandt BG et al. Infection of Cebus monkeys with Junin virus. Medicina (B Aires) 45(2), 144-152 (1985).

115 Avila MM, Samoilovich SR, Laguens RP, Merani MS, Weissenbacher MC. Protection of Junin virus-infected marmosets by passive administration of immune serum: association with late neurologic signs. J. Med. Virol. 21(1), 67-74 (1987).

116 Carballal G, Oubina JR, Molinas FC et al. Intracerebral infection of Cebus apella with the XJ-Clone 3 strain of Junin virus. J. Med. Virol. 21(3), 257-268 (1987).

- 117 Yun NE, Linde NS, Dziuba N et al. Pathogenesis of XJ and Romero strains of Junin virus in two strains of guinea pigs. Am J. Trop. Med. Hyg. 79(2), 275-282 (2008).

- Interesting animal model for arenavirus viral hemorrhagic fever using the Romero strain of Junin virus in guinea pigs that recapitulates many aspect of viral pathogenesis seen in the human disease.

118 Sanchez AB, de la Torre JC. Rescue of the prototypic arenavirus LCMV entirely from plasmid. Virology 350 (2), 370-380 (2006).

- 119 Flatz L, Bergthaler A, de la Torre JC, Pinschewer DD. Recovery of an arenavirus entirely from RNA polymerase I/II-driven cDNA. Proc. Natl Acad. Sci. USA 103(12), 4663-4668 (2006).

120 Albarino CG, Bergeron E, Erickson BR, Khristova ML, Rollin PE, Nichol ST. Efficient reverse genetics generation of infectious Junin viruses differing in glycoprotein processing. J. Virol. 83(11), 5606-5614 (2009). 